Cahiers $d u$ MONDE RUSSE

\section{Cahiers du monde russe}

Russie - Empire russe - Union soviétique et États indépendants

$49 / 4 \mid 2008$

Destins individuels et terreur. Jeunesse dans la société post-stalinienne

\title{
Gottfried Schramm, Von Puschkin bis Gorki
}

\section{Roger Comtet}

\section{(2) OpenEdition}

Journals

Édition électronique

URL : https://journals.openedition.org/monderusse/6918

DOI : 10.4000/monderusse.6918

ISSN : $1777-5388$

Éditeur

Éditions de l'EHESS

Édition imprimée

Date de publication : 28 décembre 2008

Pagination : 715-718

ISBN : 978-2-7132-2197-2

ISSN : $1252-6576$

Référence électronique

Roger Comtet, « Gottfried Schramm, Von Puschkin bis Gorki », Cahiers du monde russe [En ligne], 49/4 | 2008, mis en ligne le 23 décembre 2009, consulté le 02 septembre 2022. URL : http:// journals.openedition.org/monderusse/6918; DOI : https://doi.org/10.4000/monderusse.6918

Ce document a été généré automatiquement le 2 septembre 2022

Tous droits réservés 


\title{
Gottfried Schramm, Von Puschkin bis Gorki
}

\author{
Roger Comtet
}

\section{RÉFÉRENCE}

Gottfried schramm, Von Puschkin bis Gorki. Dichterische Wahrnehmungen einer

Gesellschaft im Wandel. Fribourg-en-Brisgau-Berlin-Vienne : Rombach, 2008, 372 p.

(Rombach Wissenschaften Reihe Litterae 159).

1 Cet ouvrage ambitieux envisage la littérature russe durant tout un siècle, de 1820 à 1920, dans ses rapports avec l'histoire tourmentée du grand Empire de l'Est pendant la même époque. Les dates qui encadrent la période retenue correspondent grosso modo aux débuts littéraires de Puškin et à la publication de la trilogie autobiographique de Gor'kij. Le point de vue adopté s'accorde avec le profil scientifique de l'auteur dont on vient de fêter le $80^{\mathrm{e}}$ anniversaire. Alors qu'il étudiait la philologie germanique à Göttingen dans les années d'après-guerre, il s'intéressait déjà à la slavistique ${ }^{1}$ et finira par se spécialiser dans l'histoire moderne de l'Europe orientale qu'il enseignera durant de longues années à l'université de Fribourg-en-Brisgau. On lui doit à ce titre de nombreuses et savantes publications ${ }^{2}$. Dans ce nouvel ouvrage, il affiche son ambition de revisiter l'histoire de la Russie à travers les témoignages des œuvres-phares de ses écrivains prosateurs.

2 La préface de l'ouvrage justifie ce propos en rappelant que la place occupée par les écrivains russes dans leur pays est tout à fait exceptionnelle. Leur voix serait en effet « la plus authentique qui soit dans le concert européen » (p. 38) et la littérature russe a connu paradoxalement son plus grand essor aux pires moments de tyrannie. Les neuf écrivains russes que l'auteur a retenus sont autant de «plumes magistrales» (Meisterfedern, p. 13), et lui paraissent les plus représentatifs pour la période envisagée : il s'agit de Puškin, Lermontov, Gogol', Turgenev, Leskov, Dostoevskij, Tolstoj et Gor'kij. Ce choix ne peut qu'emporter l'adhésion, même si la qualité littéraire des œuvres de Leskov et de Gor'kij fait encore débat. Et l'auteur de déclarer à ce propos en page 2 de couverture: "La 
littérature russe de 1820 à 1920 est un miracle dans le monde : avec les neuf étoiles qui se sont allumées les unes après les autres dans un ciel jusqu'alors obscur au-dessus d'un pays encore en retard du point de vue politique et civilisationnel». Tout cela va être développé tout au long de 14 chapitres, en se limitant strictement à des œuvres en prose. Le chapitre initial, intitulé "Une histoire éprouvée à travers des histoires imaginées " (p. 13-39) sert d'introduction à l'ouvrage en en précisant les enjeux et la méthode. Le chapitre II, «L'esprit et le pouvoir dans la vie d'Aleksandr Puškin (1799-1837)» (p. 41-58) prolonge en quelque sorte l'introduction dans la mesure où la vie de ce héros national est un véritable roman exemplaire de tous les thèmes dont l'ouvrage va traiter, à commencer par le face-à-face entre l'écrivain et le pouvoir. Suit un chapitre III, « Un dilemme politique dans les œuvres littéraires de Puškin» (p. 59-88), qui envisage les œuvres en prose, achevées ou non, où l'on voit l'écrivain, de façon extrêmement complexe, balancer « entre Pierre le Grand et Radiščev » (p. 84). Le chapitre IV porte le titre évocateur de "Un héros de notre temps - héros romanesque créé par Lermontov en 1840 : illustration du malaise d'une génération?»(p. 89-116). Le chapitre suivant est consacré aux Âmes mortes de Gogol', roman présenté comme « une œuvre grotesque au sens caché controversé » (p.117-149). L'auteur en retrace la genèse à travers les œuvres du cycle ukrainien avant d'en dégager le sens par rapport au contexte de l'époque. Avec le chapitre VI, on aborde Récits d'un chasseur, de Turgenev, publiés de 1846 à 1852, dont l'auteur aurait assumé le rôle d'un « dénonciateur de l'injustice sociale» (p. 151-185). Leskov a fourni la matière du chapitre VII en partant d'un jeu de mots sur le titre de l'un de ses romans (Nekuda [Pas d'issue]) : «En allant quelque part, en n'allant nulle part: Nikolaj Leskov en 1864 à propos des impasses que recèle un état d'esprit de rupture " (p. 187-210). L'auteur concentre ici son propos sur les romans "anti-nihilistes » où Leskov critique les idées progressistes qui rencontraient alors tant de succès dans la société russe. On passe ensuite au roman de Dostoevskij Les Démons, qualifié de «feux follets à propos du présent et ombres du passé» (chapitre VIII, p. 211-231) et qui s'inscrit dans la même perspective. Arrive alors le roman de Tolstoj Anna Karénine, "un amour condamné à l'échec » (chapitre IX, p. 233-260), centré sur la place occupée par la femme et sur la morale dominante. On revient ensuite à Dostoevskij avec La légende du Grand Inquisiteur, partie intégrante des Frères Karamazov, qui illustrerait « un règlement de comptes avec les pourvoyeurs de bonheur » (chapitre X, p. 261-282). Oncle Vania de Čehov est au centre du chapitre qui suit, consacré aux « hommes qui sont au travail » dans cette pièce (chapitre XI, p. 283-304). Et Tolstoj revient ensuite en scène avec son ultime roman Résurrection qui évoquerait « les murs qui séparent la protestation non violente de la protestation violente » (chapitre XII, p. 305-329). C'est Gor'kij qui clôt l'ouvrage à travers le roman La Mère, «roman du socialisme révolutionnaire chez des ouvriers métallurgistes "(chapitre XIII, p. 331-351) et la pièce Vassa Jeleznova (chapitre XIV, p. 353-372) dont la comparaison des deux versions successives de 1910 et 1935 est particulièrement éclairante.

3 L'ouvrage nous suggère donc bien qu'en Russie, l'écrivain est à la fois un artiste, un témoin, un guide spirituel et un prophète en vertu d'une tradition qui s'est perpétuée jusqu'à nos jours (il n'est que de penser au rôle exceptionnel encore joué récemment par Solženicyn dans la société russe). L'écrivain représente là traditionnellement comme un contre-pouvoir face à l'Etat et ses organes, quitte à en subir les conséquences (l'exil pour Puškin, Lermontov, le bagne pour Dostoevskij, l'excommunication pour Tolstoj...). Il n'y a là, à vrai dire, rien d'original, tant cela est profondément ancré dans le paysage russe. Mais l'auteur aurait pu élargir le débat en relevant que ce rôle privilégié attribué aux 
grands écrivains dans la conscience de la nation et dans les grands débats qui l'agitent semble être le propre des pays d'Europe centrale et orientale. Il suffit de penser à Mickiewicz pour la Pologne, Ševčenko pour l'Ukraine, Vuk Karadžić pour la Serbie, Sándor Petöfi pour la Hongrie, le poète France Prešeren pour la Slovénie, etc. Nul doute que cela est à rattacher au romantisme dans sa version germanique, qui a été amené à faire de la langue un attribut essentiel de la nation, comme cela a été si bien démontré par Anne-Marie Thiesse et d'autres ${ }^{3}$, et par suite à réserver un rôle exceptionnel aux écrivains qui illustrent la langue nationale en s'inspirant souvent d'ailleurs de la littérature orale considérée comme la plus authentiquement autochtone. Au lieu de se limiter au XIX ${ }^{e}$ siècle et à ses prolongements, l'auteur aurait pu ainsi évoquer le prélude littéraire du XVIII où les écrivains, dans l'ambiance des Lumières, commencent à marquer la place qui sera la leur. Le parti pris de donner la priorité à la prose risque par ailleurs de fausser le tableau puisque l'on sait bien que l'histoire de la littérature russe fait se succéder les périodes où domine la prose et celles où domine la poésie. Sur un autre plan, même si le dessein d'ensemble reste net, l'ouvrage pèche peut-être par défaut d'unité; certains chapitres reprennent en fait des articles précédemment publiés, d'où l'impression d'avoir affaire à un bouquet d'essais plus qu'à un ouvrage vraiment construit avec rigueur. C'est peut-être ce qui explique qu'on ne trouve à la fin de l'ouvrage pas plus de bibliographie générale que d'index des noms de personnes et des œuvres citées, ce que l'on regrettera.

On saura gré cependant à l'auteur de l'éclairage historique précis qu'il apporte au sujet en même temps que les références à la culture de langue allemande qu'il est tout naturellement conduit à privilégier. Par exemple, à partir de travaux récents, il est amené à tempérer le tableau très noir que brosse Tolstoj de l'institution judiciaire en Russie dans Résurrection: les réformes des années 1860 étaient passées par là et firent sentir leurs effets dès 1880, date à laquelle est située l'action du roman. Ailleurs, il s'étend sur Schiller en Russie, évoque Nietzsche, Lukács. Les lecteurs qui lisent l'allemand apprécieront aussi la qualité du style, avec une langue recherchée, personnelle, très littéraire, un grand sens de la formule, l'usage particulièrement heureux des figures de style, allitérations, métaphores etc. L'ouvrage demeure au final une contribution originale, par le point de vue adopté, à l'histoire des rapports entre littérature et société dans la Russie antérévolutionnaire. Il dépasse de loin par l'ampleur de son propos, son érudition et la pertinence de ses jugements d'autres essais du même genre, plus modestes, tel le livre de Ronald Hingley, Les écrivains russes et la société, 1825-1904, paru en $1966^{4}$. Il se révélera utile et profitable pour qui s'intéresse aussi bien à la littérature qu'à l'histoire de la Russie et mériterait peut-être d'être traduit en français. Il contribue enfin à réhabiliter l'étude des rapports entre littérature et société en Russie qu'avait discréditée la mainmise sur le sujet de la critique soviétique marxisante.

\section{NOTES}

1. Relevons qu'il a suivi les cours de Maximilian Braun (1903-1984), fils adoptif de l'illustre slavisant Friedrich Braun, élève favori d'Aleksandr Veselovskij, qui avait dirigé le département 
romano-germanique de l'université de Saint-Péterbourg avant de venir enseigner à Leipzig après la révolution russe.

2. Citons ici sa participation au Handbuch der Geschichte Russlands (Manfred Hellmann, éd., Stuttgart: Hiersemann, 1976-2004), ainsi que Anfänge des albanischen Christentums: die frühe Bekehrung der Bessen und ihre langen Folgen, Fribourg-en-Brisgau: Rombach, 1994, 270 p.; Altrusslands Anfang. Historische Schlüsse zum 9. und 10. Jahrhundert, Fribourg-en-Brisgau : Rombach, 2002, 569 p.; Slawisch im Gottesdienst : Kirchenwortschatz und neue Schriftsprachen auf dem Wege zu einem christlichen Südosteuropa, Munich : Oldenburg, 2007, $207 \mathrm{p}$.

3. Voir Anne-Marie Thiesse, La création des identités nationales. Europe XVIII ${ }^{e}-X^{e}$ siècles, P. : Seuil, 2001, 307 p.; Pierre Caussat, Dariusz Adamski, Marc Crépon, La langue source de la nation: messianismes séculiers en Europe centrale et orientale du XVIII ${ }^{e}$ au XX $X^{e}$ siècle, Liège : P. Mardaga, 1996, $539 \mathrm{p}$.

4. Ronald Hingley, Russian Writers and Society, 1825-1904, Londres : Weidenfeld \& Nicholson, 1966, 256 p. ; on peut ajouter du même auteur : Russian Writers and Soviet Society, 1917-1978, Londres : Weidenfeld \& Nicholson, 1979, 296 p. Signalons aussi, dans cet esprit, le livre de Emmanuel Waegemans, Histoire de la littérature russe : de 1700 à nos jours (trad. du néerlandais), Toulouse : Presses universitaires du Mirail-Toulouse, 2003, 391 p., qui réserve une large place au contexte historique. 